\title{
Derechos sociales y condiciones económicas de los indígenas en Colombia: de la Independencia a la República
}

\section{Social rights and economic conditions of the indigenous communities in Colombia: from Independence to the Republic}

\author{
iD Roger Pita-Pico ${ }^{1}$
}

\begin{abstract}
Resumen
El presente artículo tiene por objeto analizar el desarrollo de los derechos sociales y las condiciones económicas de la población indígena en Colombia, durante el proceso de transición del antiguo régimen español al periodo de Independencia y los primeros años de vida republicana. Para profundizar, este estudio será abordado a través de tres temáticas trascendentales en la vida de estas comunidades nativas: el desmantelamiento de las tierras de resguardo, la lucha por la exención del pago del tributo y la reivindicación de derechos y garantías sociales.
\end{abstract}

Palabras Clave: Indígenas; resguardos; tributos; Independencia; República; Colombia

\begin{abstract}
This article aims to analyze the development of social rights and economic conditions of the indigenous population in Colombia during the transition from the old Spanish regime to the Independence period and the first years of republican life. This study will address three momentous issues in the life of these native communities: the dismantling of reservations, the fight for exemption from payment of tribute and the claiming of rights and social guarantees.
\end{abstract}

Keywords: Indigenous; reservations; tributes; Independence; Republic; Colombia

Tipología: Artículo de reflexión

Recibido: 04/05/2016

Evaluado: 24/02/2017

Aceptado: 06/03/2017

Disponible en línea: 01/07/2017

Como citar este artículo: Pita-Pico, R. (2017). Derechos sociales y condiciones económicas de los indígenas en Colombia: de la Independencia a la República. Jangwa Pana, 16 (2), 253 - 266. DOI: http://dx.doi.org/10.21676/16574923.2130

1. M.Sc. en Estudios Políticos. Academia Colombiana de Historia. Colombia. Correo electrónico: rogpitc@hotmail.com. ORCID. ID: 0000-0001-9937-0228 


\section{Introducción}

\begin{abstract}
A 1 recoger datos sobre visitas e informes el historiador Hermes Tovar Pinzón (1994) llegó a cuantificar en poco más de ocho millones la población nativa de la actual Colombia hacia el año de 1500. A partir de la crucial coyuntura en que se encontraron los dos mundos, esta comunidad empezó a experimentar un drástico deterioro. Una prueba irrefutable de esta debacle demográfica es que para el censo general de 1778 solo representaban un $18.9 \%$ dentro del conjunto de la sociedad. Las cifras siguieron marcando esta tendencia decreciente en las décadas iniciales del siglo XIX.
\end{abstract}

Resulta clave anotar que durante el período colonial ya venían gestándose una serie de movilizaciones y protestas indígenas, producto de la crisis del sistema político y económico reinante. El desmejoramiento de sus condiciones de vida era más que evidente en temas tan trascendentales para ellos como las tierras de resguardos y el pago de tributos. Algunas de esas inconformidades fueron retomadas, o encontraron renovados canales de reivindicación, dentro del marco de la lucha independentista.

El presente trabajo de investigación tiene como meta profundizar en el estudio de los derechos sociales y las condiciones económicas de la comunidad indígena en Colombia, durante el periodo de transición del antiguo régimen hispánico a la fase de Independencia y los inicios del sistema republicano. Este propósito será desarrollado a través del análisis de tres temáticas específicas: el despojo de las tierras de resguardo, la solicitud de exoneración del pago del tributo y la reivindicación de derechos y garantías sociales.

Este trabajo se enmarca dentro de la corriente historiográfica de la historia social (JaramilloUribe, 1989) y el estudio de los grupos subalternos (Guha, 2013; Múnera, 2005). Se realizó con base en el método de análisis cualitativo de fuentes primarias tales como los documentos de archivo, los informes oficiales, las compilaciones normativas, los artículos de prensa y el intercambio epistolar de la época, fuentes con las cuales se intentaron aportar nuevas luces interpretativas. Todo esto complementado con fuentes bibliográficas alusivas a esta materia, en especial algunos trabajos recientes (Gutiérrez-Ramos, 2007; Sæther, 2005; Solano \& Flórez, 2011) que han reavivado el debate con motivo de la conmemoración del Bicentenario de la Independencia de las naciones hispanoamericanas.

\section{El desmantelamiento de los resguardos}

Después de la invasión española los indígenas se repartieron en encomiendas que fueron entregadas a los conquistadores (Molino-García, 1976). En 1549 la Corona ordenó la congregación de indígenas en pueblos y en las postrimerías de este siglo fueron asignados los primeros resguardos con el fin de exterminar el abuso de los encomenderos sobre la mano de obra indígena (Bonilla, 2002). En teoría, con la creación de esta institución se pretendía reponer la fuerza de trabajo y aumentar su número al permitirles vivir nuevamente bajo sus tradicionales formas de organización social. Vista desde la orilla institucional, también fue una medida que buscaba facilitar el pago del tributo $\mathrm{y}$ mejorar las posibilidades para gobernarlos $\mathrm{y}$ adoctrinarlos adecuadamente.

No obstante, en términos reales, la institución del resguardo significó el despojo de las áreas ocupadas ancestralmente por los indígenas dejándoles únicamente las que, a juicio del gobierno colonial, les eran suficientes para sus cultivos (Salcedo-Salcedo, 1993; Garrido, 2001). Fueron múltiples las razones esgrimidas por la Iglesia y la Corona española para reducir cada vez más el territorio inmemorial de los indígenas entre las cuales se encuentra la disminución poblacional, la urgencia de suministrarles un mejor gobierno y atención religiosa, el ahorro fiscal y el interés por maximizar la producción agrícola, entre otras.

Desde la creación misma de los resguardos los indígenas habían soportado una serie de abusos que los tenían sumidos en la pobreza, y con sus 
territorios milenarios notoriamente recortados. Las invasiones de intrusos no indígenas, las irregularidades en torno a los arriendos y las incesantes pretensiones por arrebatarles parte de sus suelos hacían cada vez más insostenible la supervivencia de estas comunidades.

A este sombrío panorama se le sumó la agresiva política de reducción y extinción de resguardos llevada a cabo por el fiscal Francisco Antonio Moreno y Escandón hacia el año de 1778 en la parte central y nororiental de la Nueva Granada. Como producto de estas acciones, muchas de esas tierras fueron rematadas al mejor postor y en algunas ocasiones sirvieron de espacio para la fundación de parroquias de blancos y mestizos. A la larga todo este proceso de agregación de resguardos terminó generando más dispersión y desarraigo en la comunidad indígena (Pita-Pico, 2007).

En 1781, al estallar la revuelta de los Comuneros, los indígenas inconformes buscaron la forma de hacer sentir sus clamores. Justamente, en el séptimo aparte de las Capitulaciones firmadas el 5 de junio entre el líder socorrano Juan Francisco Berbeo y el arzobispo Antonio Caballero y Góngora, se exigió de manera explícita la restitución de las superficies despojadas (BNC, Manuscritos, tomo 371, folio 82 r).

Dos semanas después, los indígenas de varios pueblos se volcaron hacia la plaza central de Santa Fe para protestar por los abusos y para exigir unánimemente el cumplimiento de los acuerdos suscritos. Ante esto, la Junta General impartió órdenes a los corregidores para que devolvieran a los indígenas las tierras de resguardo que aún no se hubiesen negociado. Al prelado se le pidió disponer lo necesario para que a estas comunidades se les restablecieran los curas, las imágenes y demás alhajas que les pertenecían. Por último, fue conferido un plazo de seis meses para que los vecinos ocupantes recogieran los frutos de sus cosechas. Se consideró en ese momento que sería un desatino extender la determinación de restitución con relación a las tierras ya vendidas a los blancos y mestizos puesto que de esta forma el Rey faltaría al contrato celebrado inicialmente.
En realidad esta falta de presión para expulsar a los blancos y mestizos pudo responder a la precaución del gobierno español ante nuevas protestas que no eran muy convenientes en esos momentos de efervescencia (Colmenares, 1997). Se recordó además que desde tiempos inmemoriales estas gentes habían permanecido al interior de aquellos repartimientos y que más bien "[...] su vecindario contribuye no poco a la civilidad de los naturales, y de respecto para contenerlos en los levantamientos que fácilmente suelen promover" (AGN, Resguardos de Santander, tomo 3, folio 264r). Lo cierto fue que la Real Audiencia terminó otorgando permiso temporal para que unos y otros cohabitaran al interior de los resguardos. En últimas, esta laxitud en la convivencia interétnica a pesar las leyes discriminatorias imperantes, lo que hizo fue atizar aún más las diferencias entre las partes.

Una vez amainaron los ánimos insurreccionales, las autoridades virreinales dilataron el reintegro de las tierras de resguardo (Herrera-Ángel, 2002). Por su parte, los nativos se mantuvieron inflexibles en sus pretensiones pero ya no con la misma unidad y poder que habían exhibido en medio del fervor de la revuelta Comunera.

$\mathrm{Al}$ acercarse los aires liberales, que trajo consigo el movimiento de Independencia, empezaron a ganar más fuerza los clamores que perseguían como solución la titulación privada de los resguardos a sus ocupantes ancestrales. Eso fue lo que se expuso en el capítulo tercero de las Instrucciones dadas en 1809 por el cabildo del Socorro a don Antonio Narváez de la Torre como diputado en la Junta Suprema de la metrópoli (BNC, Manuscritos, tomo 184 , folio $22 \mathrm{v}$ ).

Un año después, al registrarse en territorio neogranadino los primeros movimientos de autonomía política, el acta de Constitución del recién establecido Estado libre y soberano del Socorro acogió en su contenido esta propuesta (Rodríguez-Plata, 1963).

En el discurso político leído el $1^{\circ}$ de septiembre de 1810 por don Miguel Pombo, vocal de la Suprema 
Junta de Santa Fe, tras señalar los padecimientos sufridos por la raza indígena en los 300 años de poderío español, se proyectó un escenario de mayor prosperidad con base en la distribución de tierras de resguardo para que los indígenas tuvieran como propias las que ellos pudieran cultivar mientras que las sobrantes debían dividirse y venderse a propietarios pudientes con capacidad para poblarlas y cultivarlas útilmente. Lo más novedoso de la propuesta radicaba en que el valor resultante de esta venta iría a un fondo de inversión para beneficio de los propios nativos, en particular para la compra de herramientas o insumos y la dotación de un médico cirujano y de un maestro de primeras letras. Se fijó la condición de no poder vender ni enajenar el terreno hasta tanto no se cumplieran veinticinco o treinta años de su asignación (BNC, Manuscritos, tomo 184, folio 192r).

Este discurso de Pombo tuvo tan buena acogida que, en concordancia con la igualación de derechos y el otorgamiento de ciudadanía a los indígenas con restitución plena de sus derechos, la Junta Suprema de Santa Fe decidió a los pocos días distribuir en propiedad las tierras de resguardo según su justo valor y en varias divisiones de acuerdo al número de integrantes de cada familia. Tenían autorización para aprovecharlas y ponerlas a producir con la exclusiva condición de que no podían enajenarlas, donarlas o venderlas hasta tanto no pasaran veinte años, tiempo en el que se esperaba tuvieran apego al dominio y adquirieran experiencia sobre su administración, de modo que no fuera fácil engañarlos o seducirlos para despojarlos de su pertenencia territorial. Una vez logrado esto, podían disponer de esos espacios en beneficio de sus hijos o dotar sus hijas en matrimonio sin afectar la demás descendencia. De antemano la Junta se comprometió a reglamentar más en detalle sobre el método y procedimientos para llevar a cabo dicha repartición. El numeral $4^{\circ}$ ordenó además separar de la totalidad del terreno de cada resguardo un área proporcionada para el establecimiento y dotación de una escuela pública para la instrucción de los naturales (AGN, Historia, tomo 11, folio 226r).

Amparados en estas disposiciones los indígenas de Onzaga, en jurisdicción de la provincia de
Vélez, solicitaron a la Junta Revolucionaria del Socorro la restitución de sus resguardos (AGN, Gobierno Civil, tomo 26, folio 362v). Pero, para desdicha de ellos, jamás abrazarían ese sueño por cuanto quedaron irremediablemente reducidos a la condición de agregados de la nueva parroquia que llevaba el mismo nombre.

Finalmente las medidas adoptadas durante esta primera fase republicana quedaron truncadas a partir de 1815 tras la reconquista del poder por parte de los españoles. La siguiente historia sintetiza muy bien el impacto generado por la inestabilidad política y jurídica suscitada durante estos años. E1 2 de octubre de 1818, las autoridades indígenas del pueblo de Coyaima en la provincia de Mariquita remitieron una carta al virrey Juan Sámano solicitándole encarecidamente el inmediato cumplimiento de una superior providencia en la que su antecesor había resuelto quitarle el poder que ejercían los alcaldes blancos sobre esa comunidad, es decir, que los indígenas volvieran a tener gobernantes de su misma etnia tal como ocurría antes de la primera fase independentista. Esta petición la sustentaron con base en el capítulo 13 de la Ordenanza de Intendentes, en donde se les autorizaba elegir legítimamente cada año sus propios jueces. Este mandato había sido infringido por el gobernador de la provincia quien por intereses personales y económicos seguía nombrando representantes blancos, señalados por los indígenas como culpables de continuos maltratos.

Los naturales llamaron además la atención sobre el hecho de que El Guamo, Ambalema, Ataco y Venadillo habían dejado de ser pueblos indígenas para transformarse en parroquias de blancos, produciéndose la dispersión de aquellos habitantes ancestrales, con lo cual el Real erario dejaba de captar una buena cantidad de tributos. El siguiente es apenas un fragmento del testimonio de la querella expuesta:

[...] estamos viendo que cada día más y más libres se agregan a nuestro pueblo, los indios se despueblan, nuestro Rey pierde sus derechos, los fandangos no cesan, las embriagueces se au- 
mentan, los amancebamientos son públicos, los robos mucho más, [los no indios] se apoderan de nuestras minas y labores, y si algo les decimos, nos majan a palos (AGN, Gobierno Civil, tomo 35 , folio $518 \mathrm{v})$.

A mediados de 1819 los alcaldes y capitanes indígenas del pueblo del Cocuy denunciaron al corregidor del partido de Chita en la provincia de Tunja por haberles exigido 140 pesos por concepto de los arrendamientos de las zonas que ellos mismos ocupaban para beneficio propio, impidiéndoles sembrar hasta tanto no hicieran efectivo este pago. Creían los afectados descabellada y arbitraria esta medida, y más si se tiene en cuenta que se habían caracterizado por el correcto cumplimiento de sus deberes; aparte de los notables servicios prestados a los regimientos del Monarca durante la campaña militar de Reconquista a través del abastecimiento de frutos, harinas, cabalgaduras, muebles, raciones e incluso contribuyendo al aseo de los alojamientos o en el trabajo de maleteros.

El funcionario sindicado don Francisco Javier Angarita calificó de falsas y tendenciosas estas imputaciones arguyendo que lo único que él había hecho era apremiarlos por el atraso en los tributos, así tuvieran que recurrir a las utilidades dejadas por los arriendos. En su dictamen, el fiscal encargado del proceso ordenó se verificara que el alquiler solo debía aplicarse a los sobrantes de los resguardos, dejándole a los nativos el área suficiente para cultivar, autosostenerse y responder por sus obligaciones tributarias (AGN, Gobierno Civil, tomo 36, folios 741r-751r).

Con la batalla de Boyacá del 7 de agosto de 1819 los patriotas emprenden la recuperación definitiva del poder y sientan las bases de una República independiente. Es durante esta fase cuando empezó a sellarse el proceso de extinción de resguardos.

En respuesta a la gran cantidad de abusos y al abandono padecido por los indígenas durante el régimen de dominio hispánico, el presidente Simón Bolívar ordenó el 20 de mayo de 1820 que en el término de cinco años había que devolverles, como propietarios legítimos, todas las tierras que formaban sus resguardos por encima de cualquier alegato o título presentado por los actuales poseedores. Una vez recuperados estos territorios debían distribuirse proporcionalmente entre las familias. Si hechas estas reparticiones quedaban áreas sobrantes, se arrendarían en remate dando prioridad a los actuales tenedores o inquilinos. Las familias indígenas solo podían alquilar la parte que les correspondiera con previo conocimiento del juez político para evitar daños y fraudes. Los productos de los arrendamientos debían ser destinados exclusivamente para el pago de tributos y para el sostenimiento de los maestros de las escuelas establecidas en cada pueblo (LópezDomínguez, 1990a; Martínez-Garnica, 1993).

Ese mismo año Juan Ubaldo Chiriví, gobernador de los indígenas del pueblo de Firavitoba en la provincia de Tunja, presentó al general Bolívar una súplica para que los protegiera de las extorsiones y abusos cometidos contra ellos. Aún no se había acatado fielmente la directiva que ordenaba restituirles los títulos del resguardo. Por el contrario, habían sido víctimas de un complot orquestado por el comisionado, un eclesiástico y el administrador de las contiguas haciendas de La Compañía y Las Monjas para cercenar parte del territorio indígena.

Dicho comisionado, quien había sido corregidor en el tiempo del dominio español, hostilizaba constantemente a los indígenas y se negaba a entregarles las escrituras hasta tanto ellos no le pagaran 16 pesos de su salario. Por su lado, el corregidor y juez político arrendaba parte del resguardo pero sin dar cuenta a los naturales de estos réditos. Aunque se había elevado la respectiva denuncia sobre el comportamiento indebido de estos dos funcionarios, las autoridades provinciales en vez de amparar a los afectados, procedieron a castigarlos inmisericordemente. Quedó entonces en evidencia la connivencia entre estas instancias de poder. Agobiada por estas vicisitudes, la comunidad indígena experimentó un proceso de progresivo empobrecimiento.

Enterado de lo delicado del asunto, Bolívar impartió instrucciones al gobernador de 
Tunja para que protegiera esta y todas las demás poblaciones indígenas de la provincia, debiendo propender para que no se molestaran estos territorios ancestrales sino que más bien se procurara ensancharlos cuando así fuera necesario (Acotaciones Bolivarianas, 1960). El 12 de febrero de 1821 el Libertador nuevamente conminó a dicho gobernante a garantizar la ejecución de la citada ley sobre el reintegro de los resguardos a los naturales y su equitativo repartimiento. Esta medida la reiteró Bolívar para calmar las incesantes quejas y clamores de todos los pueblos por donde había transitado, en donde se percató de que, en vez de mejorar el estado de estas comunidades, se habían convertido en pequeños reductos (Cortázar, 1969).

El alquiler de las tierras sobrantes de los resguardos también suscitó reacciones y quejas entre los habitantes ancestrales de estos suelos. En 1820 los indígenas de Guacamayas solicitaron se les permitiera disfrutar de las rentas de los arriendos cuyo valor estaba estimado en 100 pesos anuales, dinero que les sería muy útil para el sostenimiento del culto divino. Para ellos esta concesión representaba un paliativo ante la crítica penuria económica que padecían como producto del acoso y opresión ejercida por el antiguo régimen español. Mensualmente, y por largo tiempo, fueron forzados a aportar a las tropas realistas diez cargas de harina y menestra, una buena cantidad de raciones, 20 peones para maletas, mano de obra para la refacción de caminos y construcción de trincheras. Agravaba aún más la situación el tener que reunir lo del pago del tributo (AGN, Indios, tomo 1 , folios $120 \mathrm{r}-125 \mathrm{v}$ ).

Al momento de llevarse a cabo el proceso de restitución de resguardos, en el pueblo de Lenguazaque se presentaron en marzo de 1821 algunas quejas de los indígenas contra algunos vecinos que se hallaban en calidad de arrendatarios en algunas de las tierras sobrantes. En este caso, las autoridades provinciales fueron muy enfáticas en reiterar el derecho que tenían los nativos de rematar estas tierras para su propio beneficio (AHRB, Archivo Militar, tomo 4, folios 54r-56r). El 11 de octubre de 1821 el Congreso de Cúcuta ratificó la disolución de los resguardos entendidos como propiedad comunitaria de los indígenas al establecer que estas tierras serían distribuidas de manera individual entre las cabezas de familias indígenas. Para cumplir este propósito el gobierno debía formar el censo de cada pueblo indígena y debía además elaborar un informe sobre la extensión y los límites del resguardo. La ley abrió además la posibilidad de que individuos de cualquier otra condición étnica pudiesen asentarse al interior de los resguardos pagando para ello el respectivo arrendamiento pero sin perjudicar a los indígenas en sus sementaras (Codificación Nacional, 1924). En cierto modo, estas disposiciones significaron el rompimiento de la vida comunal al perderse la base territorial.

En desarrollo del artículo $5^{\circ}$ de esta ley, el 17 de febrero de 1822 el secretario del Interior don José Manuel Restrepo impartió instrucciones a cada uno de los departamentos de la República para que los jueces políticos de cada cantón realizaran la medición de los resguardos y formaran la lista de las cabezas de familias con derecho a la distribución. Estos funcionarios debían superar todos los inconvenientes con el fin de garantizar una repartición equitativa y el pago de los costos que implicara este proceso.

Tal como lo indica el informe de las diligencias adelantadas en los cantones de San Gil y Vélez, se observa cómo las labores de medición no estuvieron exentas de dificultades tanto logísticas como técnicas. No en todos los casos se contaba con expertos que llevaran a cabo este trabajo y no siempre se usó la misma medida de referencia. Lo valioso de estas diligencias es que permitió detectar problemas de fondo que venían manifestándose desde vieja data tales como la presencia de vecinos intrusos, la utilización de esos espacios de resguardo para otros usos y la existencia de una gran cantidad de tierras no aptas para la producción agropecuaria (AGN, Miscelánea de la República, tomo 123, folios 1r-69r).

Al cabo de algunos años todo parecía indicar que la medida sobre repartición de tierras no se había cumplido a cabalidad en todos los resguardos. Así se deduce del informe anual que presentó en 1826 el entonces Secretario del Interior al Congreso de 
la República. Se creía indispensable, por tanto, tramitar una nueva ley en la que se fijaran las bases que habrían de aplicarse en dicha distribución. La experiencia observada por este alto funcionario lo había persuadido de la importancia de acompañar a los nativos en el proceso para asegurar que la distribución fuera justa, de acuerdo al tamaño y tipo de suelo. Por ello propuso, al máximo ente legislador, una prórroga de cinco años para la ejecución de la medida (Restrepo, 1826).

Durante estos primeros años de vida republicana los intereses se centraron no solo en las tierras de resguardos sino en las que ocupaban los indígenas "salvajes", bajo el objetivo que se había propuesto el gobierno de poblar el territorio y de impulsar el progreso y desarrollo económico hasta en sus más recónditos lugares. Así sucedió en noviembre de 1824 cuando el Congreso Nacional estudió la propuesta del coronel Mauricio Encinoso de comprar unos terrenos en la Guajira. Según el concepto del Consejo de Gobierno, esta era una solicitud viable en vista de que allí los indígenas eran errantes y ocupaban un espacio mayor del que necesitaban (Acuerdos del Consejo, 1988).

Finalmente, hacia 1832, la mentalidad liberal reinante terminó triunfando al estipular de manera definitiva la parcelación y titulación individual de los antiguos resguardos (Martínez-Garnica, 1993). Rápidamente los nativos se vieron expropiados de sus espacios $\mathrm{y}$, por consiguiente, quedaron disponibles como fuerza laboral en haciendas y estancias vecinas (Díaz-De Zuluaga, 1986; Solano \& Flórez, 2011).

\section{La carga de los tributos}

El tributo era una cantidad fija que todo adulto indígena mayor debía pagar a la Corona. Por lo general se debía cumplir con dos tributos anuales, uno en Navidad y el otro en San Juan (Eugenio-

2. Estos nativos habitaban en zonas lejanas e inhóspitas, desconocían el idioma y las costumbres españolas, y se hallaban por fuera de los parámetros del ordenamiento social y político colonial. Sobre ellos era más complicado ejercer el control debido a su carácter bravío y al hecho de que muchas veces vivían dispersos o eran nómadas.
Martínez, 1977). Aun cuando se registrara un declive demográfico en la comunidad indígena no obstante permanecía incólume el total del valor a tributar, lo cual los exigía a multiplicar sus esfuerzos. Así mismo, a medida que avanzaba el período colonial, aumentaban los lamentos de los indígenas ante el sufrido afán por pagar el tributo.

Al llegar el año de 1781 surgió una luz de esperanza en torno a la insurrección de los Comuneros. En el numeral $7^{\circ}$ de las Capitulaciones firmadas con el gobierno virreinal, se planteó que debido a que la estrechez económica les impedía a los nativos satisfacer el tributo exigido con tanto celo, se pidió entonces rebajarlo a cuatro pesos (BNC, Manuscritos, tomo 371, folio 82r). En el punto 15 se exigió revocar la recién expedida orden Real que los obligaba a contribuir con un peso, además del acostumbrado tributo. Infortunadamente estas propuestas que hubiesen representado un alivio para la comunidad indígena, finalmente no prosperaron al ser reprimida la revuelta.

Con la entrada del primer experimento republicano emergieron algunas voces que creían justo librar a los indígenas total o al menos parcialmente de dicha carga. El caleño don Ignacio Herrera, uno de los signatarios del acta del 20 de julio de 1810, avivó el debate a través de sus reflexiones expuestas en septiembre de 1809 al diputado neogranadino que debía asistir a la Junta Central de España:

Los tributos que pagan los indios, claman también por reforma $[\ldots]$ ¿Y por qué se les sujeta como esclavos a un tributo innecesario? Mejor es dejarlos libres, que paguen las alcabalas y demás impuestos del Estado. Entonces desenvolverán sus talentos, trabajarán con más utilidad en la labor de las tierras, pondrán telares y se destinarán a las artes útiles y necesarias de que ahora están separados (Arciniegas, 1972, p. 70).

El 24 de septiembre de 1810 la Junta Suprema conformada en la ciudad de Santa Fe concedió varios privilegios a los nativos, uno de los cuales consistía en derogar la obligación "odiosa" del tributo quedando en adelante equiparables en todas las prerrogativas y exenciones vigentes para 
los demás ciudadanos (AGN, Historia, tomo 11, folio 225r). Ese mismo alivio tributario se ratificó a nivel provincial. Ese mismo año, al proclamarse el acta de Constitución del recién establecido Estado libre y soberano del Socorro, se abolió este gravamen (Rodríguez-Plata, 1963). Hacia 1812 el Poder Legislativo del Estado Provincial de Antioquia declaró a los indígenas como "ciudadanos libres de tributo".

Muy poco tiempo duraron vigentes estas medidas pues serían anuladas tras la invasión militar de los españoles y la instauración de la fase de Reconquista. Sin duda, con el recrudecimiento de las guerras de Independencia, se agudizaron mucho más las condiciones materiales de las comunidades indígenas. Las contribuciones extraordinarias, el auxilio a las tropas, las fugas y la ocupación de no pocos indígenas como reclutas o en otras actividades ligadas al conflicto militar, fueron factores que los distrajeron de sus faenas diarias de subsistencia. Así las cosas, cada vez más se veían en aprietos para cumplir con el deber de sufragar dicho impuesto. Lo anterior dio lugar a frecuentes solicitudes dirigidas al gobierno de turno para que se les congraciara con exoneraciones o condonaciones.

Algunos de los beneficios se obtuvieron en reconocimiento a acciones directas en el campo de batalla. Tal fue el caso ocurrido en 1813 con los indígenas cercanos a la ciudad de Santa Marta, quienes recibieron del Rey una rebaja de un peso en el pago de tributos por su decidida participación en contra de las facciones insurgentes (OcampoLópez, 1989). Según el concepto emitido por el fiscal del Consejo de Indias, resultaba más útil en la coyuntura de guerra el servicio prestado por estos nativos que el menoscabo que sufrirían las cajas reales con tan nimia rebaja (Restrepo, 1975).

Hacia 1817 los indígenas del pueblo de Gámeza, en la provincia de Tunja, expusieron su constante servicio y lealtad al Rey ocupando sus personas $\mathrm{y}$ ofreciendo sus haberes para las tropas realistas. Aparte de las consignaciones en efectivo, se trajo a colación una extensa lista de auxilios que incluían cabalgaduras para las brigadas y artillerías, disposición de sus casas como hospedaje para los milicianos, raciones, ganados, trigo, carne, varios frutos y granos (arveja, habas y fríjol) transportados a los llanos. A esto se le sumaba la labor de muchos de ellos como cargadores de maletas y portadores de cartas y documentos secretos.

En razón a estos apreciables servicios, y a la promesa hecha por el Pacificador Pablo Morillo de ayudarles en caso de apuros, los indígenas no dudaron en recurrir a la compasión del virrey Juan Sámano para que los eximiera del tributo correspondiente al año de 1816, el cual no habían podido pagar debido a la miseria padecida y a las dificultades para subsistir y alimentar sus familias. Todos los antecedentes planteados fueron debidamente comprobados por el cura Juan Ramírez y el protector de naturales (AGN, Indios, tomo 1 , folios $65 \mathrm{r}-67 \mathrm{v}$ ).

Una situación bien distinta ocurrió en esa misma provincia en el pueblo de Güicán, cuyos nativos estaban recién cristianizados y se ubicaban en una zona de frontera entre las cumbres de la cordillera Oriental y los llanos del Casanare. Ellos lanzaron en 1817 una amenaza a las autoridades coloniales en el sentido de que si la Corona no accedía a la excepción del tributo, ellos retornarían a las montañas en sus antiguos territorios $y$ permanecerían alejados del dominio español. Finalmente, el fiscal de turno terminó accediendo a las peticiones de esta comunidad (EspinosaMoreno, 2010).

Una vez adquirida la independencia política gracias a la victoria lograda en la batalla de Boyacá, al interior del gobierno republicano se planteó en diciembre de 1819 el interés de librar a los indígenas de la carga tributaria pero el presidente Simón Bolívar decidió aplazar este beneficio en razón a la crisis económica y al estado de devastación causado por la ofensiva española. En mayo del año siguiente se optó por perdonar a los nativos que estuvieran en mora, esto con el fin de aliviar la suerte de esta población y porque además 
se reconoció que existían ciertas dificultades para efectuar el cobro (López-Domínguez, 1990a; AGN, Libros Manuscritos, tomo 6, folio 44r).

Finalmente, a través de la ley promulgada el 11 de octubre de 1821, el Congreso de Cúcuta fue muy claro en afirmar que en adelante los indígenas no pagarían el impuesto "conocido con el degradante nombre de tributo" (Codificación Nacional, 1924). Pero aún con esta gracia, a las oficinas del gobierno central seguían llegando innumerables peticiones de exoneración del gravamen. A estas alturas del conflicto gran parte de la población estaba exhausta de las contribuciones y de los efectos de la guerra, al tiempo que continuaban las exigencias para mantener la libertad y terminar de expulsar a los realistas aún presentes en la región del sur y en la costa Caribe. En términos generales no hubo uniformidad en la respuesta oficial a cada uno de los clamores.

En 1820 los nativos de Nobsa en la provincia de Tunja solicitaron la exoneración de tributos como recompensa por haber contribuido con dinero, frutos, raciones y servicios personales al Ejército Libertador. Bolívar fue muy enfático en aclararles que ellos, y muchos pueblos más, habían realizado inmensos sacrificios de manera que si se les relevaba del pago debía hacerse lo mismo con todos, lo cual iba en franco detrimento de las arcas del naciente Estado republicano que apenas contaba con exiguos recursos para sentar las bases de la estructura administrativa de la nación y para mitigar los onerosos gastos acarreados en medio del conflicto. Sin embargo, en aras de la piedad, se decidió en esta ocasión exceptuarlos (AGN, Libros Manuscritos, tomo 6, folios 106r-110v).

Por esas calendas, en esa misma provincia, los integrantes del repartimiento de Turmequé hicieron llegar al presidente Simón Bolívar en su cuartel general de Ventaquemada, una carta en la que impetraban se les redimiera del tributo o por lo menos se les condonara aquellos pagos que no habían podido efectuar. A pesar de haber soportado la presión del cobro por parte del corregidor, les era imposible responder debido a las desdichas económicas y necesidades que soportaron durante los últimos tres años del régimen español (Acotaciones Bolivarianas, 1960).

En ese mismo año, el vicepresidente Francisco de Paula Santander decidió relevar del tributo a los indígenas de los pueblos del cantón de Ocaña en la provincia de Santa Marta por su corta población y por su comprobado estado de miseria (AGN, Libros Manuscritos, tomo 6, folio 82v). Los alcaldes y demás naturales del pueblo de Coyaima en la provincia de Mariquita se quejaron de que aún no se había dado cumplimiento a la disposición promulgada el 22 de abril de 1820, mediante la cual el Libertador Simón Bolívar los eximía del tributo. Esta era una petición angustiante de esta comunidad que se veía en peores condiciones que en los pasados tiempos de la opresión española. Dentro de los auxilios prestados a las tropas patriotas, se contabilizaron 200 caballos para transporte de fusiles y pertrechos, además de los suministros de sal, plátano y carne. Para efectos de apaciguarles en algo la cruda situación de escasez Bolívar determinó en un principio que aquellos que hubiesen entregado contribuciones extraordinarias a la causa patriota serían exentos del impuesto (Acotaciones Bolivarianas, 1960). Finalmente, en abril de 1821, se halló justo el reclamo de estos indígenas bajo el entendido de que tenían que pagar a la vez como tributarios y como ciudadanos (Cortázar, 1969).

En mayo de ese mismo año, a pocas leguas de allí, los nativos de Natagaima también acudieron ante el gobierno central para rogar por la exención de tributos, y aunque el corregidor los inquietaba continuamente por este hecho, no habían podido responder por no tener tiempo ni siquiera para sembrar. La razón esencial de este trance obedecía al contexto mismo de la guerra, ya que por quedar su pueblo en la ruta habitual de las tropas, se habían visto irremediablemente obligados a brindarles oportuno auxilio y alojamiento. En repetidas veces fueron utilizados en el servicio de posta y en jornadas de arriería. Se lamentaban también de los saqueos a que fueron sometidos tanto por los patriotas como por los realistas (AGN, Indios, tomo 1 , folios $927 \mathrm{r}-935 \mathrm{v})$. 
El $1^{\circ}$ de enero de 1822 el Congreso de la República reiteró que en lo venidero los nativos no pagarían tributo y en materia de impuestos quedaban equiparados a los demás ciudadanos, rigiéndose bajo las mismas reglas (Gaceta de Colombia, 1822).

Convencido de que la abolición del tributo había traído consecuencias negativas, el presidente Simón Bolívar decidió el 15 de octubre de 1828 restablecer este gravamen. No obstante esta medida quedaría prácticamente derogada al disolverse la Gran Colombia (Gutiérrez-Ramos, 2001).

\section{Derechos y garantías en entredicho}

En materia de derechos y garantías esta etapa de Independencia estuvo llena de contrastes. Todavía en 1820 los funcionarios consideraban a los indígenas como "estúpidos" y los clasificaban moral e intelectualmente como niños (LópezDomínguez, 1990). Aunque la ley marcó algunos avances, especialmente durante las dos fases del gobierno republicano, lo cierto es que en la práctica faltaba aún mucho camino para alcanzar una igualdad real y efectiva.

En 1810 la Junta Suprema de Santa Fe resolvió elevar los indígenas a la categoría de ciudadanos permitiéndoles el acceso a los empleos de la República y la posibilidad de ser condecorados con honores y premios por sus méritos y conductas. De esta manera se pretendía unificar la ley y el gobierno para todos los habitantes (AGN, Historia, tomo 11 , folio $225 \mathrm{r}$ ).

Desde luego estas nuevas noticias causaron curiosidad. Al momento en que el corregidor Luis Eduardo Azuola comunicaba después de la misa mayor a los nativos de Soacha sus nuevos derechos adquiridos, estos manifestaron su júbilo con abrazos y lágrimas (AGN, Historia, tomo 15, folio 161r). Empero, no todas las reacciones fueron así de pacíficas. En Cocuy el cura don Josef Santiago Crispín y Pérez denunció la mala interpretación dada al bando sobre igualdad entre blancos e indígenas (AGN, Historia, tomo 12, folio 542r).
En el Acta Constitucional del Estado libre y soberano del Socorro del 15 de agosto de 1810 se declaró que desde ese día los indígenas entraban en sociedad con los demás ciudadanos de la provincia a gozar de iguales libertades y derechos, a excepción del derecho de representación que sólo obtendrían hasta que "adquirieran las luces necesarias para hacerlo personalmente" (Rodríguez-Plata, 1963). En la Constitución de Cundinamarca promulgada en 1812 se estableció que los indígenas gozarían de todos los derechos de ciudadanos y quedaban con voz y voto en las elecciones (Const., 1812).

En el periodo de la Reconquista española no hay registros de haberse presentado progresos significativos en materia de derechos para los indígenas pues prácticamente se restableció la condición jurídica vigente antes de 1810 .

Nuevos avances se registraron a partir de 1819 al imponer definitivamente su poderío los republicanos. En el decreto expedido el 20 de mayo de 1820, por el presidente Simón Bolívar, se dispuso que ni los curas ni los jueces políticos o funcionarios podían servirse de los naturales sin pagarles salarios acordados mediante contratos. El que infringiera esta disposición estaría conminado a desembolsar el doble del servicio hecho, cuya multa sería entregada inmediatamente al agraviado.

Desde el momento mismo de emitido este decreto debían cesar "como escandalosas y contrario al espíritu de la religión, a la disciplina de la Iglesia y a todas las leyes" tres prácticas indebidas: la de negarse a administrar los sacramentos a los feligreses indígenas que no hubiesen cancelado los derechos de cofradía y congrua, la de obligarlos a que hicieran fiestas a los santos y la de exigirles derechos parroquiales de lo cual estaban exentos por el estipendio que el Estado giraba a los curas. En adelante, los nativos, así como los demás habitantes de la República, podían circular con sus pasaportes, comerciar sus frutos y ejercer sus trabajos y talentos sin cortapisas (LópezDomínguez, 1990a). 
En octubre de 1821 el Congreso de la República fijó nuevas disposiciones en materia de justicia. Los protectores de naturales continuarían ejerciendo sus funciones promoviendo acciones comunales, pero las demás causas civiles y criminales las debían enfrentar los indígenas como los demás ciudadanos considerados en la clase de "miserables", en cuya virtud no se les cobraría derecho alguno. Desde ese día quedaban supeditados no a los cabildos indígenas sino a los jueces de las parroquias (Gaceta de Colombia, 1822). Para mayor alivio, fue abolida la degradante práctica de azotarlos públicamente.

En razón a varias denuncias presentadas por el protector de indígenas sobre varios abusos cometidos contra los indígenas de la provincia de Bogotá, el intendente de Cundinamarca, dictó el 14 de febrero de 1824 un decreto dirigido a los jueces políticos de su departamento. Allí se recordó el artículo $2^{\circ}$ de la ley del 8 de octubre de 1821 en el que se establecía que los curas de los pueblos indígenas no debían exigir de ellos ninguna cantidad por concepto de rogativas, fiestas, procesiones ni otro acto de devoción. Por consiguiente quedaban exentos de trabajar en los cultivos de comunidad, cuyos productos se destinaban para gastos extraordinarios de la iglesia. Siendo los indígenas igual al resto de ciudadanos, no debían ser destinados al servicio particular de los curas o jueces seculares contra su voluntad, quedando prohibido obligar a las jóvenes solteras a servir en la casa cural. En caso de necesitar servicio personal, los doctrineros debían proceder a contratar a los indígenas al igual que se hacía con cualquier otro ciudadano (El Correo de Bogotá, 1824).

Durante estos primeros años de vida republicana se planteó de nuevo el interés por la educación de este segmento de la población. Se tenía el convencimiento de que la formación era clave para sacarlos de la ignorancia en que se hallaban sumidos desde los tiempos del dominio español. En el decreto expedido el 20 de mayo de 1820 por el presidente Simón Bolívar, se estipuló que los indígenas cuyas edades oscilaran entre los 4 y los 14 años debían ingresar a la escuela con el fin de que aprendieran a leer y escribir y además para que asimilaran las nociones básicas de aritmética, religión y derechos y deberes del ciudadano.

Al cabo de cinco meses el vicepresidente Santander dictó un nuevo decreto en el que reiteró la responsabilidad de los gobernadores, autoridades políticas locales y curas para que aseguraran la formación educativa de los nativos (Osorio-Racines, 1969).

Los obstáculos en el acceso educativo de la comunidad indígena aumentaron ostensiblemente en los niveles superiores de formación. Durante estos inicios del periodo republicano se decidió otorgar cuatro becas a indígenas "puros" en los colegios seminarios de Bogotá, cuatro más en Quito y otro tanto en Caracas, con el requisito de que debían saber leer y escribir. De los fondos públicos se le daría anualmente 120 pesos a cada becado para su vestimenta y demás gastos necesarios (Gaceta de Colombia, 1822). Con este avance la intención del gobierno era que los graduados fueran profesionales y sirvieran de ejemplo a sus congéneres en aras de la libertad y la igualdad (Restrepo, 1826).

Al momento de hacer un balance general hay que reconocer que fue muy limitado el impacto de las medidas adoptadas por el Estado republicano para incluir a los indígenas en sus planes de expansión educativa. En la práctica el gobierno central no se mostró muy interesado en vigilar que sus órdenes fueran finalmente cumplidas, al tiempo que no se observó en las autoridades regionales una verdadera voluntad política (PitaPico, 2014).

\section{Discusión y conclusión}

Los efectos devastadores de las guerras de Independencia en la población indígena fueron más que evidentes: descenso demográfico, acentuamiento de su crisis económica, resquebrajamiento de su unidad familiar y social, pérdida progresiva de su preciado legado étnico y el desvanecimiento de sus costumbres y de su 
saber milenario. Sin lugar a dudas, los continuos cambios de gobierno registrados durante esta etapa generaron mayor confusión e inestabilidad jurídica.

El proyecto liberal republicano se extendió también hacia la población indígena al imponerse la supresión del tributo y de las tierras colectivas en el intento por equipararlos como ciudadanos libres y propietarios privados (Martínez-Garnica, 2006). No obstante, como bien ha reiterado en sus trabajos el historiador Jairo Gutiérrez Ramos (2001), el proyecto republicano de incorporación de los indígenas a la nación como ciudadanos libres e iguales no estuvo exento de obstáculos debido a las dificultades administrativas y a la resistencia misma de las comunidades indígenas.

Desafortunadamente la llegada de los republicanos al poder no satisfizo todas las expectativas que tenían los indígenas tras haber ofrendado una alta cuota de sacrificio en el objetivo de contribuir a la formación de una nueva República. Por el contrario, su ya reducido número se hallaba arrinconado en pequeñas áreas y postrado en la pobreza. Existen varias pruebas que dan testimonio de ello. La sala capitular de Iscuandé, en carta dirigida al general Bolívar en 1828, le hizo saber cómo a pesar de haber sido los nativos exceptuados del tributo y derechos parroquiales, se hallaban más abandonados que antes: "[...] si trabajan lo hacen por cebar el vicio de la bebida. Viven desnudos, cubierta la honestidad de un pedazo de corteza de palo, y así es que jamás han sido útiles para nada ni lo serán tampoco para el Estado" (AGN, Ministerio de Hacienda, tomo 244, folio 305v).

A través del estudio de las temáticas tratadas en este artículo puede palparse en el fondo el choque de mentalidades que seguía aún vigente en algunos sectores de la sociedad, particularmente entre aquellos que seguían defendiendo la segregación y la discriminación, y aquellos otros que eran partidarios de la libertad y la igualdad social. No es fortuito entonces que, aún en los primeros años de vida republicana, siguió percibiéndose en algunos funcionarios una falta de voluntad política y de coordinación institucional para aplicar cabalmente las ideas progresistas estipuladas por la ley. Entre tanto, el segmento mayoritario de blancos y mestizos intentó por todos los medios mantener su poderío social y económico, cuyos intereses iban muchas veces en detrimento de las reivindicaciones de las comunidades nativas.

Al culminar el proceso de Independencia la etnia indígena era prácticamente una minoría relegada. El balance en el transcurso de estos años de convulsión e inestabilidad no podía ser para ellos más desalentador. Fueron, a decir verdad, más los fracasos que las oportunidades y faltarían mucho años y otras tantas luchas sociales para que estas comunidades alcanzaran plenamente su condición de ciudadanos con iguales derechos que el resto de colombianos.

\section{Referencias bibliográficas}

Acotaciones Bolivarianas. (1960). Decretos marginales del Libertador (1813-1830). Caracas: Fundación John Boulton.

Acuerdos del Consejo de Gobierno de la República de Colombia, 1821-1824. (1988). (Tomo I). Bogotá: Biblioteca de la Presidencia de la República.

Archivo General de la Nación (AGN). BogotáColombia. Fondos: Gobierno Civil, Historia, Indios, Libros Manuscritos y Leyes Originales de Colombia, Ministerio de Hacienda, Miscelánea de la República.

Archivo Histórico Regional de Boyacá (AHRB). Tunja-Colombia. Fondo Archivo Militar.

Arciniegas, G. (1972). Colombia: itinerario y espiritu de la Independencia. Bogotá: Biblioteca Banco Popular.

Biblioteca Nacional de Colombia. BogotáColombia. Fondo Manuscritos.

Bonilla, H. (2003). Reseña del libro Tierra y Comunidad. Un problema irresuelto. El caso del altiplano cundiboyacense (Virreinato de la Nueva Granada) 1750-1800. Anuario Colombiano de Historia Social y de la Cultura, 30, 369-372. 
Circular. (1824, 26 de marzo). El Correo de Bogotá, p. 55.

Codificación Nacional de todas las leyes de Colombia desde el año de 1821. (1924). (Tomo I) Bogotá: Imprenta Nacional.

Colmenares, G. (1997). La Provincia de Tunja en el Nuevo Reino de Granada. Ensayo de Historia Social 1539-1800. Santa Fe de Bogotá: Tercer Mundo Editores.

Constitución de la República de Cundinamarca [Const.]. (1812). Santafé: En la Imprenta de D. Bruno Espinosa de los Monteros, por D. Nicomedes Lora.

Cortázar, R. (1969). Correspondencia dirigida al General Santander. Bogotá: Academia Colombiana de Historia.

Decreto del Gobierno. (1822, 5 de mayo). Gaceta de Colombia, p. 1.

Díaz-de Zuluaga, Z. (1986). La fuerza de trabajo en el Cauca Grande, 1810-1830. En G. Colmenares. (Edit.), La Independencia. Ensayos de Historia Social (pp. 25-67). Bogotá: Colcultura.

El Congreso de Colombia. (1822, 3 de marzo). Gaceta de Colombia, p. 1.

Espinosa-Moreno, N. F. (2010). La cultura política de los indígenas del norte de la provincia de Tunja durante la Reconquista española. Anuario de Historia Social y de la Cultura, 37 (1), 121-148.

Eugenio-Martínez, M. A. (1977). Tributo y trabajo del indio en la Nueva Granada. Sevilla: Escuela de Estudios Hispano-Americano.

Garrido, M. (2001). América y España en el concierto de naciones. En M. Garrido. (Ed.). Historia de América Andina, [El sistema colonial tardío], (pp. 23-58), Quito: Universidad Andina Simón Bolívar.
Guha, R. (2013). Prefacio a los estudios subalternos. En R. Rodríguez. (Comp.), Estudios Subalternos: una cartografia a (des)tiempo (pp. 73-74). Popayán: Editorial Universidad del Cauca.

Gutiérrez-Ramos, J. (2001). El proyecto de incorporación de los indios a la nación en la Nueva Granada, 1810-1850. Anuario de Historia Regional y de las Fronteras, 6, 203-222.

Gutiérrez-Ramos, J. (2007). Los indios de Pasto contra la República (1809-1824). Bogotá: Instituto Colombiano de Antropología e Historia.

Herrera-Ángel, M. (2002). Ordenar para controlar. Ordenamiento espacial y control político en las Llanuras del Caribe y en los Andes Centrales Neogranadinos, siglo XVIII. Bogotá: ICANHAcademia Colombiana de Historia.

Jaramillo-Uribe, J. (1989). Ensayos de Historia Social. Bogotá: Tercer Mundo-Ediciones Uniandes.

López-Domínguez, L.H.(1990). Administraciones de Santander 1820-1825. Bogotá: Biblioteca de la Presidencia de la República.

López-Domínguez, L. H. (1990a). De Boyacá a Cúcuta. Memoria Administrativa, 18191821. Bogotá: Biblioteca de la Presidencia de la República.

Martínez-Garnica, A. (1993). El Régimen del Resguardo en Santander. Bucaramanga: Gobernación de Santander.

Martínez-Garnica, A. (2006). La agenda liberal temprana en la Nueva Granada (18001850). Bucaramanga: Universidad Industrial de Santander.

Molino-García, M. T. (1976). La encomienda en el Nuevo Reino de Granada durante el siglo XVIII. Sevilla: Escuela de Estudios Hispano-Americanos. 
Múnera, A. (2005). Fronteras imaginadas. La construcción de las razas y de la geografía en el siglo XIX colombiano. Bogotá: Editorial Planeta.

Ocampo-López, J. (1989). El proceso político, militar y social de la Independencia. En Nueva Historia de Colombia, Bogotá: Editorial Planeta S.A.

Osorio-Racines, F. (1969). Decretos del General Santander. 1819-1821. Bogotá: Universidad Nacional.

Pita-Pico, R. (2007). El remate de resguardos en el nororiente neogranadino durante el siglo XVIII. Boletín de Historia y Antigüedades, 94 (839), 725-748.

Pita-Pico, R. (2014). La exclusión étnica en la educación básica y secundaria en la naciente república de Colombia, 1819-1825, Revista Historia de la Educación Colombiana, 17 (17), 79-100.

Restrepo-Tirado, E. (1975). Historia de la Provincia de Santa Marta. Bogotá: Colcultura.

Restrepo, J. M. (1826). Exposición que el Secretario del Despacho del Interior de la
República de Colombia hace al Congreso de 1826, sobre los negocios de su Departamento. Bogotá: Imprenta de Manuel M. Viller-Calderón.

Rodríguez-Plata, H. (1963). La antigua provincia de Socorro y la Independencia. Bogotá: Biblioteca de Historia Nacional.

Sæther, S.A. (2005). Identidades e Independencia en Santa Marta y Riohacha: 1750-1850. Bogotá: Instituto Colombiano de Antropología e Historia, 2005.

Salcedo-Salcedo, J. (1993). Los pueblos de indios en el Nuevo Reino de Granada y Popayán. En R. Gutiérrez. (Coord.), Pueblos de indios. Otro urbanismo en la región andina (179-203). Quito: Ediciones Abya-Yala.

Solano, S. P. \& Flórez Bolívar, R. (2011). Resguardos indígenas en el Caribe Colombiano durante el siglo XIX. Procesos Históricos, 19, 72-95.

Tovar-Pinzón, H. (1994). Convocatoria al poder del Número. Santa Fe de Bogotá: Archivo General de la Nación. 